\title{
ARENA OLAHRAGA BASKET
}

\author{
Hieronimus Richard ${ }^{1)}$, Budi Adelar Sukada ${ }^{2)}$ \\ 1) Program Studi S1 Arsitektur, Fakultas Teknik, Universitas Tarumanagara, hieronimoes.richard@gmail.com \\ 2) Program Studi S1 Arsitektur, Fakultas Teknik, Universitas Tarumanagara, budisukada@yahoo.com
}

\begin{abstract}
Abstrak
Kawasan Cengkareng merupakan Kawasan yang memiliki kepadatan penduduk tertinggi di daerah Jakarta Barat. Banyaknya jumlah bangunan perumahan dan permukiman di Kawasan Cengkareng menyebabkan ruang publik yang tersedia masih terbilang kurang cukup untuk mengakomodasi penduduk di Cengkareng. Fasilitas-fasilitas hiburan pun sangat jarang ditemui di Kawasan Cengkareng. Oleh karena itu, dibutuhkan sarana wisata yang dapat mengakomodasi kebutuhan rekreasi bagi penduduk di Kawasan Cengkareng. Rekreasi itu sendiri ada banyak jenisnya, salah satunya adalah rekreasi olahraga basket. Olahraga basket, selain dapat menjadi salah satu gaya hidup yang sehat, olahraga basket juga dapat menjadi salah satu pertunjukan ataupun aktivitas permainan yang menyenangkan. Namun, hal tersebut tidak didukung oleh sarana yang memadai, terutama untuk di Kawasan Cengkareng. Minimnya jumlah sarana olahraga basket di Kawasan Cengkareng sangat berbanding terbalik dengan minat penduduk di sekitarnya. Untuk itu penulis mengkaji dan menganalisis tentang Kawasan Cengkareng dalam merancang sarana wisata olahraga basket. Dengan mengutamakan permainan olahraga basket sebagai suatu pertunjukan dan permainan yang menyenangkan, lapangan basket sebagai arena permainan dibuat dapat diakses oleh publik dan dapat terlihat dari sebagian besar area pada kawasan tapak. Sebagai suatu objek wisata, selain lapangan basket, fasilitas-fasilitas pendukung lainnya juga dimasukan ke dalam program, seperti restoran, retail, gym, dll agar dapat dinikmati oleh pengunjung dan membuat program yang diterapkan dapat lebih hidup.
\end{abstract}

Kata kunci: Arena, Basket, Permainan, Pertunjukan, Wisata Olahraga

\begin{abstract}
Cengkareng is an area that has the highest population density in West Jakarta. The large number of residential buildings in the Cengkareng has caused public space relatively less to accommodate residents in Cengkareng. Entertainment facilities are also very rare in the Cengkareng area. Therefore, tourism facilities are needed that can accommodate recreational needs for residents in the Cengkareng Region. There are many types of recreation itself, one of which is basketball. Basketball, in addition to being one of the healthiest lifestyles, basketball can also be one of the performances or fun game activities. However, this is not supported by adequate facilities, especially in the Cengkareng. The lack of a number of basketball facilities in the Cengkareng area is very inversely proportional to the interest of the surrounding population. To the authors review and analyze the Cengkareng Region in designing basketball sports tourism facilities. By prioritizing basketball as a performance and fun game, the basketball court as a playing area is made accessible to the public and can be seen from most areas of the site. As a tourist attraction, beside basketball courts, other supporting facilities are also included in the program, such as restaurants, retail, gym, etc. so that visitors can enjoy it and make the program implemented more alive.
\end{abstract}

Keywords: Arena, Basketball, Game, Performance, Sport Tourism

\section{PENDAHULUAN}

Jakarta sebagai kota dengan kepadatan penduduk yang tinggi, dirasakan masih sangat kurang dengan objek wisata sebagai sarana rekreasi. Jumlah objek wisata yang terdapat di Jakarta masih belum dapat mengakomodasi kebutuhan rekreasi dari penduduk Jakarta, 
terutama untuk kalangan ekonomi rendah. Hal ini tentu akan berpengaruh pada kehidupan sosial penduduk.

Oleh sebab itu, dibutuhkan suatu wadah rekreasi yang dapat digunakan oleh sebagian besar kalangan masyarakat di Jakarta, terutama untuk kalangan yang memiliki ekonomi yang rendah. Olahraga basket merupakan salah satu solusi yang dapat diterapkan untuk menanggapi permasalahan ini. Selain sebagai kegiatan rekreasi yang murah, olahraga basket juga merupakan kegiatan yang menyehatkan karena menggunakan seluruh bagian dari tubuh (Dian, 2018).

Pada perkembangannya, olahraga basket berevolusi menjadi permainan yang menyenangkan dan atraksi yang dapat dinikmati. Misalnya seperti permainan Slam Ball (Lihat Gambar 1). Permainan ini dapat dinikmati oleh pengunjung yang ingin mencoba melakukan dunk shoot ke dalam ring basket

Namun, pada kenyataannya fasilitas olahraga basket masih terbilang kurang baik dan kurang terawat. Misalnya seperti retakan pada lantai lapangan basket (Lihat Gambar 2). Hal ini dapat menyebabkan pengguna fasilitas basket menjadi kurang nyaman dan membahayakan pemain basket dalam bermain basket. Padahal peminat basket di Jakarta, baik dalam bermain basket, maupun yang menikmati dengan menonton pertandingan atau permainan basket juga cukup tinggi.

Oleh sebab itu, dengan mengacu pada teori Architourism, diharapkan olahraga basket dapat menjadi solusi gaya hidup sehat, menjadi suatu atraksi dan sarana rekreasi bagi penduduk di Jakarta.

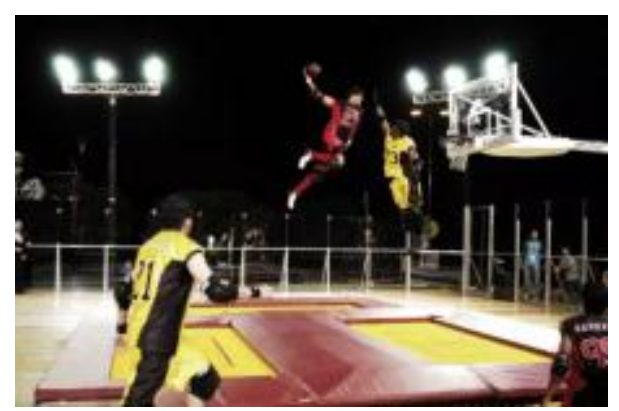

Gambar 1. Permainan Slam Ball

Sumber: https://res.cloudinary.com

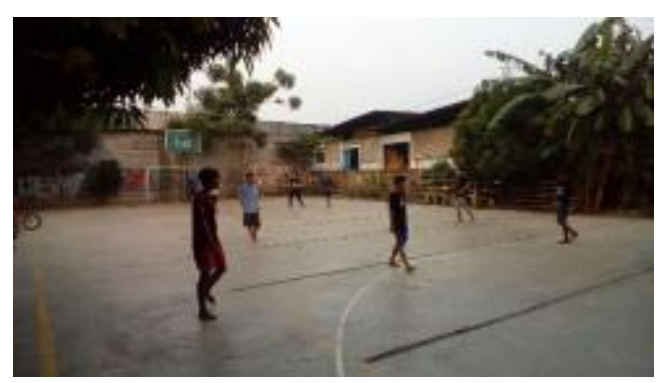

Gambar 2. Foto Keadaan Lapangan Basket Angasana Raya di Cengkareng Timur, Jakarta Barat

\section{KAJIAN LITERATUR}

Architourism dapat diartikan sebagai suatu destinasi wisata dimana terdapat peran arsitektur di dalamnya. Dalam architourism terdapat 2 definisi penting, yaitu: Tourism Architecture (Arsitektur Wisata) yaitu program yang muncul dari arsitektur dalam mendukung kegiatan wisata di dalamnya dan Architectural Tourism (Wisata Arsitektur) yaitu arsitektur yang berperan sebagai objek / bentuk yang dapat mendapat atraksi dan pusat dari kunjungan wisatawan (Sutanto, 2018). 
Sebagai suatu sarana wisata, objek wisata harus dapat menampilkan suatu atraksi dan memenuhi keinginan dari wisatawan atau pengunjung yang datang sehingga dapat memberikan kesan tersendiri terhadap objek wisata yang dikunjunginya. Dalam bidang pariwisata, citra dari objek wisata yang jelas merupakan suatu keunggulan tersendiri di mata para pengunjung. Simbol atau tanda sangatlah diperlukan dalam objek wisata untuk menunjukkan apa yang diharapkan pengunjung dari objek wisata (Specht, 2014).

Arena merupakan tempat dimana pertandingan, persaingan, ataupun perjuangan dilaksanakan (KBBI, 2019). "Arena: central or area that used for sports or other forms of entertainment, and surrounded by seats for spectators" (Dictionary, 2019). Arena merupakan tempat berlangsungnya pertandingan olahraga yang dijadikan sebagai pertunjukan oleh pengunjung dengan menonton di sekeliling pertandingan olahraga berlangsung.

Basket merupakan permainan dengan mengunakan bola yang dimainkan oleh 2 tim regu yang terdiri atas 5 orang dengan cara memasukkan bola ke dalam ring (KBBI, 2019). "Basketball is a game that played by two teams of five players on rectangular court having goal by shoot to the ring at each end" (Dictionary, 2019).

\section{METODE}

Metode yang diterapkan adalah metode kualitatif melalui studi kepustakaan dari beberapa proyek stadion olahraga basket, serta studi literatur sebagai acuan dalam menentukan luasan program ruang yang diterapkan, serta melakukan pengamatan terhadap fasilitas lapangan basket di kawasan Jakarta.

\section{DISKUSI DAN HASIL}

Lokasi tapak yang dipilih berada di Kawasan Cengkareng, Jakarta Barat karena melihat keadaan lapangan basket di Cengkareng masih kurang baik, padahal minat penduduk di daerah tersebut sudah cukup tinggi (Lihat Gambar 2). Selain itu, kawasan Kecamatan Cengkareng juga merupakan kecamatan dengan kepadatan penduduk tertinggi di Jakarta Barat dimana merupakan kota dengan kepadatan penduduk tertinggi di DKI Jakarta (Lihat Tabel 1 dan 2). Banyaknya sekolah dan universitas di daerah Cengkareng juga menjadi salah satu faktor terpilihnya daerah Cengkareng menjadi lokasi tapak dibangunnya Arena Olahraga Basket (Lihat Gambar 3).

Tabel 1. Kepadatan Penduduk di DKI Jakarta

\begin{tabular}{lcc}
\hline $\begin{array}{l}\text { Kabupaten/ } \\
\text { Kota }\end{array}$ & $\begin{array}{c}\text { Presentase } \\
\text { Penduduk }\end{array}$ & $\begin{array}{c}\text { Kepadatan } \\
\text { Penduduk } \\
\text { per km2 }\end{array}$ \\
\hline $\begin{array}{l}\text { Kepulauan } \\
\text { Seribu }\end{array}$ & 0,23 & 2683,96 \\
\hline $\begin{array}{l}\text { Jakarta } \\
\text { Selatan }\end{array}$ & 21,48 & 15472,17 \\
\hline $\begin{array}{l}\text { Jakarta } \\
\text { Timur }\end{array}$ & 27,94 & 15124,15 \\
\hline Jakarta Pusat & 8,98 & 18993,11 \\
\hline Jakarta Barat & 24,2 & 19017,92 \\
\hline Jakarta Utara & 17,17 & 11913,83 \\
\hline \multicolumn{2}{r}{ Sumber: https://jakarta.bps.go.id/ }
\end{tabular}

Gambar 3. Peta Lokasi Sekolah di sekitar Tapak Sumber: https://www.google.com/maps/search/sekolah

Tabel 2. Kepadatan Penduduk di Jakarta Barat 


\begin{tabular}{lc}
\hline Kecamatan & $\begin{array}{c}\text { Jumlah Penduduk } \\
\text { Hasil Proyeksi (Jiwa) }\end{array}$ \\
\hline Kembangan & 300802 \\
\hline Kebon Jeruk & 357788 \\
\hline Palmerah & 202373 \\
\hline Grogol & 232697 \\
Petamburan & 239474 \\
\hline Tambora & 110008 \\
\hline Taman Sari & 555972 \\
\hline Cengakreng & 431296 \\
\hline Kalideres & \multicolumn{1}{c}{ Sumber: https://jakbarkota.bps.go.id/ }
\end{tabular}

Berdasarkan teori Architourism, Arena Olahraga Basket harus dapat mampu menarik perhatian dan memberikan kesan tersendiri kepada pengunjung sehingga dapat memberikan pengalaman berbeda sebagai bagian dari wisata dan menjadikan Arena Olahraga Basket sebagai salah satu alternatif wisata bagi penduduk di Jakarta.

Konsep dan tema dari Arena Olahraga Basket diambil dari pemikiran bahwa olahraga permainan basket, selain sebagai suatu permainan, basket dapat menjadi suatu atraksi pengunjung yang memiliki ketertarikan terhadap permainan basket agar mampu mempertahankan kepopuleran basket di mata penduduk. Dari pemikiran tersebut, perancang membuat lapangan basket yang dikelilingi oleh jalur sirkulasi pengunjung sehingga pengunjung dapat melihat atraksi permainan basket di lapangan basket (Lihat Gambar 5, 6, dan 9).

Bentuk bangunan dibuat menyerupai bentuk bola basket yang masuk ke dalam keranjang ring basket agar pengunjung dapat mengenali bahwa bangunan objek wisata ini merupakan arena olahraga basket. Bentukan bola basket yang masuk ke dalam ring basket juga merupakan implementasi dari tujuan dalam pertandingan basket yaitu, memasukkan bola basket ke dalam ring basket.

Arena pertandingan basket, Area latihan, beserta fasilitas pendukungnya seperti ruang ganti dan shower dibuat dalam bentukkan bola basket, Area fasilitas publik, seperti retail dan gym dibuat dalam bentukan ring basket, sedangkan Area lobi pengunjung dibuat di bagian depan agar lebih menonjol.

Berikut merupakan hasil rancangan yang berupa denah, tampak, dan potongan, serta perpektif bangunan dengan berkonsep pada permainan basket sebagai suatu atraksi pertunjukan, yang menghasilkan konsep void pada lantai 2 sehingga dapat melihat permainan basket di ruang latihan yang berada di lantai 1 (Lihat Gambar 5-12).

Gambar 4. Bentukkan Massa Arena Olahraga Basket

Gambar 5. Denah Lantai 1 (Area latihan, Retail, Game Arcade)

Gambar 6. Denah Lantai 2 (Lobby Entrance, Restoran, Retail) yang diberikan void di tengah agar dapat melihat permainan basket di area latihan 
Gambar 7. Denah Lantai 3 dan 4 (Arena Basket, Ruang VIP)

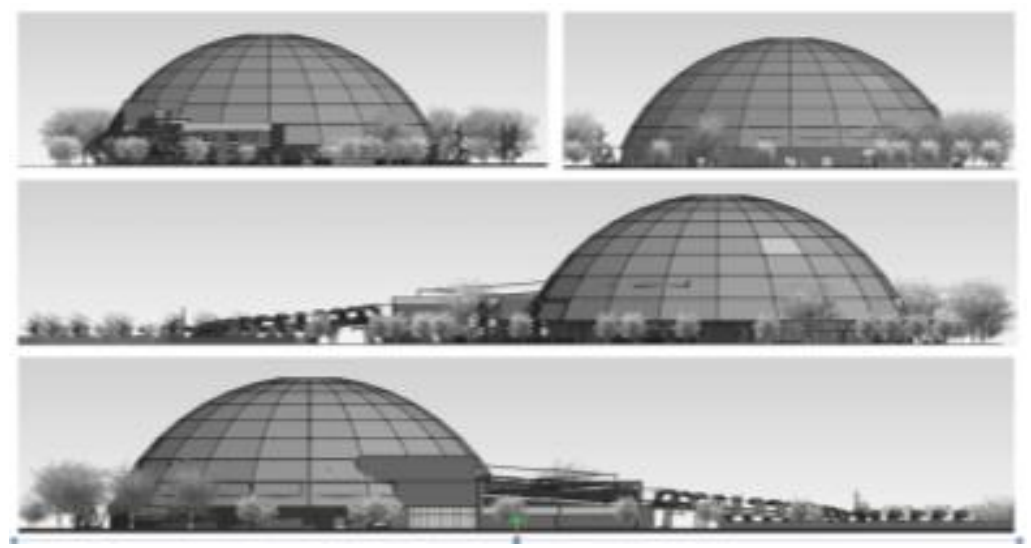

Gambar 8. Penampilan Tampak Bangunan

Gambar 9. Penerapan konsep void di atas lapangan basket dalam pembentukan proyek
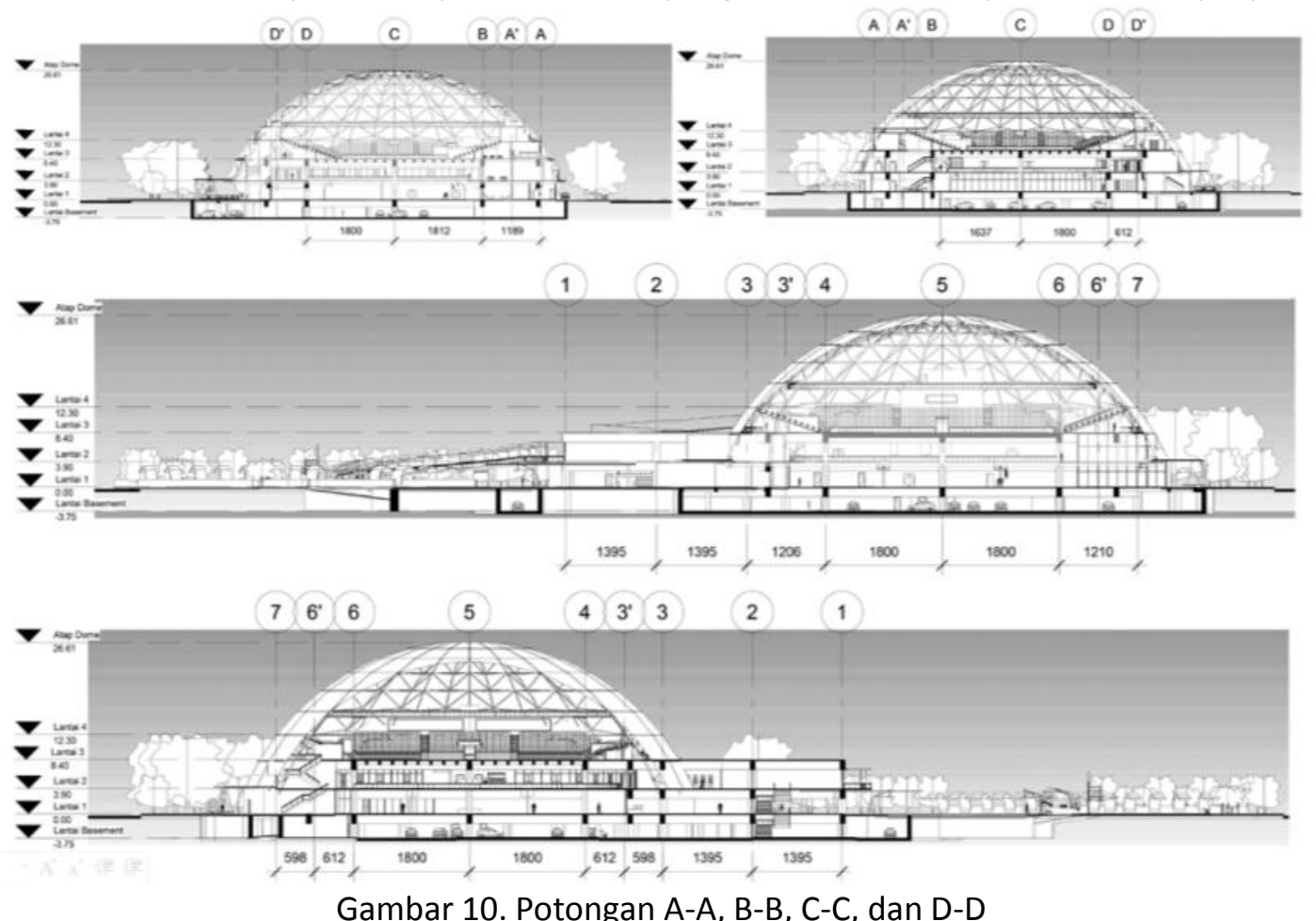

Gambar 11. Perspektif Eksterior Plaza Pedestrian 

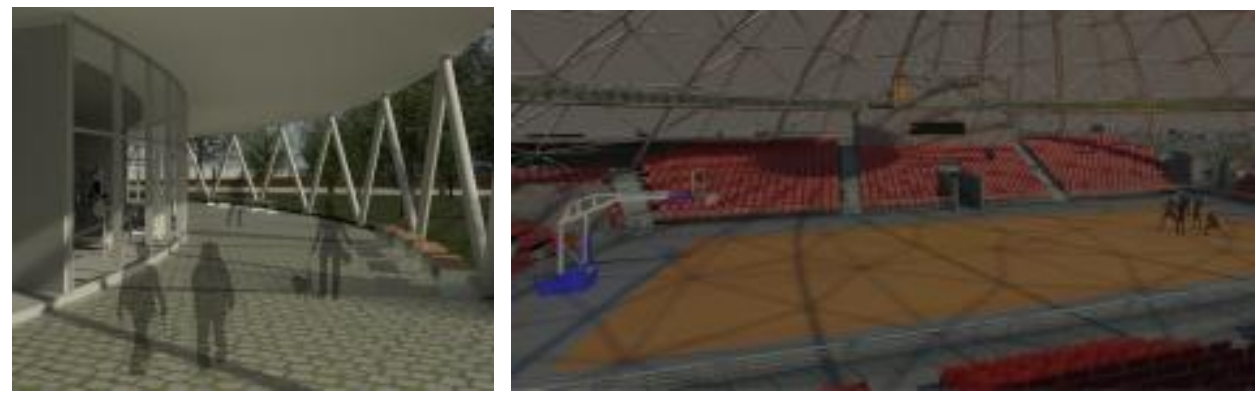

Gambar 12. Perspektif Food Retail (kiri) dan Arena Basket (kanan)

\section{KESIMPULAN DAN SARAN}

Bangunan yang memiliki konsep bentukkan bola basket dan ring basket sangat sesuai diterapkan dalam bangunan arena olahraga basket. Konsep bentukkan ini sangat menunjukkan bahwa bangunan arena olahraga basket merupakan bangunan yang memiliki fasilitas basket di dalamnya. Sehingga pengunjung akan lebih mudah mengenali bangunan ini. Area latihan yang berada di lantai 1 yang dapat terlihat dari area sirkulasi pengunjung di lantai 2 membuat pengunjung yang berada di area sirkulasi dapat menikmati permainan latihan basket yang dilakukan oleh atlet basket, terutama bagi para penggemar basket. Arena Olahraga Basket yang diletakkan di daerah Cengkareng, Jakarta Barat juga dapat menampung minat penduduk di sekitar daerah Cengkareng dalam bermain basket dimana belum memiliki lapangan basket yang sesuai faktor kenyamanan.

\section{REFERENSI}

Badan Pusat Data Statistik Kota Jakarta Barat. (2018, April 21). Dipetik dari https://jakbarkota.bps.go.id

Badan Pusat Statistik Provinsi DKI Jakarta. (2018, April 21). Dipetik dari https://jakarta.bps.go.id

Dian, I. U. (2018, Oktober 11). Wartakota. Dipetik dari 5 Manfaat Kesehatan saat Bermain Bola Basket Bersama Teman-teman: http://wartakota.tribunnews.com/2018/10/11/5-manfaatkesehatan-saat-bermain-bola-basket-bersama-teman-teman

Dictionary. (2019, Januari 5). Dipetik dari Dictionary: https://www.dictionary.com/browse/arena

KBBI. (2019, Januari 5). Dipetik dari KBBI: https://kbbi.web.id/

Specht, J. (2014). Architectural Tourism: Building for urban travel destination. Munich, Jerman: Springer Gabler.

Sutanto, A. (2018). Architourism = Program + Bentuk. Architourism, 5-7.

Wicaksono, P. (2018, April 30). Sport Tempo. Dipetik dari Basket NBA: Akademi Pelatih Jr Didik para Guru di Yogyakarta: https://sport.tempo.co/read/1084347/basket-nba-akademipelatih-jr-didik-para-guru-di-yogyakarta. 